\title{
Humanistic Care in the Design of Social Welfare Institutes
}

\author{
Mao Mao \\ College of Science and Technology, China Three Gorges University, Yichang, 443002, China
}

\author{
Keywords: Social welfare institutes, Environment, Difference, Humanistic care, Safety
}

\begin{abstract}
Currently, the design of most of social welfare institutes in China is very easy, and only the most fundamental interface processing is completed; both interior and exterior environment are monotonous and cold. As the main service object in welfare institutes, this socially disadvantaged group also needs more psychological care and comfort except for needing more care in daily life. Currently, the environment of social welfare institutes can only meet basic survival demand, and it is hard for them to make them obtain the sense of belonging and sense of identity. Therefore, how to fully meet their psychological demand and create a comfortable environment of social welfare institutes full of humanistic care while the users' basic life demand is met is the problem which shall be urgently solved at present. This paper will combine with the design cases to explain how to reflect humanistic care in the interior and exterior environment of social welfare institutes.
\end{abstract}

\section{Introduction}

China is a country with a large population; currently, the total population is almost 1.4 billion. With continuously deepening of aging of population in China, the proportion of quantity of aging population in total population will continuously increase, and there is an obvious trend that the aging population has large foundation, quick growth, old aging, disability, and empty nest. Furthermore, in consideration of China's national condition and miniaturization structure, the problem of supporting old people is very severe. The great pressure of aging of population tests the ability of government planning in supporting old people.

According to statistics, by the end of 2008, China had 37,623 various kinds of old-age welfare institutes, and 2.45 million old-age beds, which only accounted for $1.5 \%$ of aged population above 60 years old; this proportion was not only lower than the proportion (5\%-7\%) in developed countries, but also lower than the level (2\%-3\%) in some developing countries. Besides, expect for guaranteeing old people's basic life, we also need large quantity of professional care service in old people's psychology and medicine. The future development of care for old people shall be that the old people's living guarantee gradually becomes socialized, and the way of family supporting becomes the way of social supporting; the government support will become the big trend. Although the institutes for old-age care play a supplementary role in China's old-age welfare service system, they have big function. With economic development and social progress, especially with the aging of population, family miniaturization, and rural urbanization, people will have larger and large demand on old-age service. As for old-age institutes and facilities established by government, the government shall continue to expand the investment, try to improve the condition of facilities, and gradually improve the level of old-age service according to the level of local economic development and the condition of old people who need support by public welfare institutes. Besides, the government shall encourage and support the social civilian-run public facilities for the elders, and formulate preferential policies to actively develop welfare-oriented public facilities for the elders to form a security system for old people under hard family supporting. ${ }^{[1]}$

The main task of social welfare institutes is to adopt "three-without" old people, orphaned and disabled children, and abandoned babies to implement the work policy of supporting, curing, and education, guarantee the legal rights and interests of social vulnerable groups, and maintain social stability. Therefore, from perspective of design of environmental art, the social welfare institutes can be regarded as human residential environment which takes two kinds of specific social group (old people and children) as main service object. 
However, a good and comfortable living environment shall be applied with "gentle methods and force", that is, on one hand, it shall have suitable spatial size, complete function division, unobstructed line for stream of people, and reasonable barrier-free design; on the other hand, it shall have rich visual landscape, warm and sweet environmental atmosphere, and the matching of color and texture shall meet users' aesthetic taste and psychological demand. Although Chinese governments at different levels gradually expand the investment in public welfare institutes, the exterior and interior environment and facilities of welfare institutes are still simple and crude, and they are far from being designed. The welfare institutes generally can only meet the basic functional requirements, and they are deficient in meeting the psychological demand of main service object, and creating environmental atmosphere and visual landscape, and they commonly lack of humanistic care, which causes the situation that the old people and children who reside in welfare institutes can't satisfy their mental demand and obtain the sense of belonging; they lack of necessary humanistic care. Compared to young adults, as vulnerable groups, the old people and children shall obtain more care in terms of satisfying psychological demand so that the old people can spend their remaining days happily and the children can grow up healthily.

In order to create a comfortable and beautiful environment of social welfare institutes, we shall fully consider the particularity of the service object in physiology and psychology. The old people have seen a great deal of life and clam personality, they prefer quietness, and it is not suitable for them to accept high-strength activities and stimulating color and light; besides, the old people are commonly unable to move freely, thus it is required to pay special attention to barrier-free access and security supporting facilities. The children have strong curiosity and lively personality, and like sports; they are sensitive to bright color and easily get hurt in activities, thus it is required to pay special attention to the security against collision and falling. Besides, due to big difference between old people and children in age, there is also extreme difference in their psychological demand and individual hobbies. The humanistic care refers to respecting people's dominant position and individual difference, showing care to people's colorful individual demand, stimulating people's initiative, enthusiasm, and creativity, and promoting people's free and all-around development. Therefore, in the design process, the designer shall coordinate the difference in behavioral mode and personality between two groups, meet their respective mental and physiological demand, and provide them with biggest humanistic care so that they can be happy to live in the environment of welfare institutes. The following part will combine with the overall design scheme of one social welfare institute completed by the student under the author's guidance to carry out specific discussion:

\section{Complete function}

Due to the fact that the social welfare institutes undertake the responsibility of supporting, curing, and education for old people and children, the prime task of design is to fully know the functional composition of social welfare institutes to ensure a complete function and space. The social welfare institutes shall meet the residents' demand such as residing, catering, curing and treatment, entertainment, infant care, education, and relaxation, the staffs' daily office demand, and the coordinative demand of relevant department.

Specifically speaking, the floor I of a social welfare institute shall be set with porch, hall, lobby, information office, reception desk, monitoring room, elevator room, salvation office, consulting room, emergency room, drug room, recovery room, mess hall, compartment, kitchen, public toilet and other functional space (area); the floor II shall be set with some guest rooms and staff's office (dean's office, staff's office, conference room, lecture hall, and exhibition hall, etc.); except for guest rooms, each floor shall be set with television room, reading room, chess and card room, calligraphy room, hairdressing saloon, fitness room, and other relaxation-oriented functional space; the floor for children (infant) shall be set with classroom, children's entertainment room, nursery room and other functional space; each floor shall be set with duty room, water heater room, public toilet and other functional space; as for the public land out of social welfare institute, it is required to carry out suitable landscape planning and design according to terrain and climate so as to fully meet old people 
and children's demand of outdoor activities, landscape viewing, playing, relaxation, communication, entertainment, and gathering, etc.

\section{Reasonable division}

The main service objects of social welfare institutes include old people and children, and it has been mentioned above that there is great difference in their behavioral mode and psychological demand. The old people like quietness, and most of them are unable to move freely; the children like to move up and down and they are keen about new things. Besides, there is also great difference in nursing level and living way between disabled people and healthy people. Therefore, in the process of spatial division, it is required to carry out overall planning and reasonable division. The division in specific design is implemented as below:

\section{Division of living space}

From perspective of nursing level, physical condition, personality and habit, and lifestyle, it is required to set special recovery building for disabled old people and children, and the proportion and level of nursing, medical space and security facilities shall increase accordingly; meanwhile, the guest rooms for old people and children shall be set by floor. The guest rooms for old people shall be set in middle and low floors as much as possible (floor 2-4); in consideration of physical condition, the older the old people are, the lower floor we shall select for them. The guest rooms for children shall be set in middle and high floors (floor 5 and above); in consideration of good physical agility, the older the children are, the stronger their self-esteem is, thus their rooms shall be selected at high floor.

\section{Division of public space}

As for the public space such as mess hall, reading room, chess and card room, calligraphy room, and classroom in social welfare institutes, it is required to fully consider the difference in age structure and physical condition to carry out reasonable division. As for dining space in mess hall, we shall set independent children's dining area or children's restaurant, suitably reduce the height of dining table and chair, and carry out circular-bead treatment according to children's size. The common dinning area mainly satisfy the dinning of healthy old and young people, and the dining table and chair with standard specification shall be adopted. Furthermore, we shall independently set the dining area for disabled people, expand the space between dinning tables and the space between dining table and gallery, and not set dinning chair to ensure the travelling and positioning of wheelchairs. As for other relaxation and education space, we shall also set the special area for disabled people to ensure all people's safety and comfort.

\section{Division of landscape space}

As the important place for residents' outdoor viewing, activities, relaxation, and gathering, the environmental landscape design of welfare institute shall be also done with proper dividing treatment except for overall landscape sequence, and design and planning of landscape level. As for the activity area mainly for old people, we shall adopt nature-style landscaping technique, fully consider the shading and relaxation facilities, match group planting with chairs and pavilion, or set the gallery which is planted with climbing planting, and provide shallow-water landscape to create a secluded and refined environment, which is good for old people to carry out relaxation, chatting, viewing, and other activities (as shown in Figure 1). As for activity area for children, it is suitable to reserve clear an open lawn, sand pit, and small square, set recreation facilities and fitness equipments, provide flowering shrub or plant fence as isolation strip, and adopt plastic materials for ground pavement so as to prevent from falling, which is good for children's game, fitness, and making friends and other activities (as shown in Figure 2). Meanwhile, as for outdoor landscape area, we shall also consider barrier-free design and safety facilities such as ramp, sidewalk for the blind, handrail, and containment. 


\section{Safe facility}

Due to specific age structure of service object of social welfare institute, there is high requirement for security. In order to ensure that the old people, children, and disabled people can move safely and conveniently, except for common fireproofing materials, fire control and evacuation, anti-falling and other safe measures, the designer shall also consider following aspects:

\section{Barrier-free design}

The public space shall include barrier-free design; as for social welfare institutes, due to specific service objects, it is required to fully consider the rationality of barrier-free design according to Code of Building Design for Old People and Barrier-free Design Specification, such as indoor and outdoor barrier-free entrance and ramp design, passage width design, corridor chair rail design, design of corner cut or circular bead at turning, design of lift car suitable for stretcher and wheelchair, barrier-free special toilet, barrier-free bathing room, and outdoor sidewalk for the blind.

\section{Anti-skidding and anti-collision design}

In consideration of the fact that the old people decline in their somatic function and the children are active, the safe and anti-skidding materials shall be selected for outdoor and indoor ground, and the anti-collision design shall be considered for corner and corner angle. As for outdoor ground, it shall be paved with water permeable brick and anti-skidding brick; as for indoor ground, it shall be paved with anti-skidding floor, and the guest room can be paved with carpet. The toilet and shower room shall be paved with ship-and-galley tile and matched with anti-skidding mat. As for the public space and habitation space in welfare institute, the anti-collision design shall be considered; at the corner of corridor and corner angle of furniture, it is required to carry out circular-bead treatment or carry out soft-material treatment.

\section{Handrail and containment design}

In consideration of children's size, a special design shall be made for staircase handrail, balcony, and guard bar. The staircase shall be installed with handrail at both sides, and the primary and secondary handrail shall be designed. The height of primary handrail shall be $900 \mathrm{~mm}$ for adult's use, and the height of secondary handrail shall be 500mm for children's use; in order to prevent children from falling, the protection facilities for windowsill of exterior window and balcony shall be not lower than $1,100 \mathrm{~mm}$, and the distance between vertical member bars of protective barrier shall be not larger than $110 \mathrm{~mm}$. Besides, in the children's guest rooms, it is not suitable to place mobilizable furniture and articles, and set the position and distance of furniture and exterior window to prevent children from climbing up windowsill.

\section{Nursing design}

In order to guarantee old people and children's safety and provide similar medical space, it is required to arrange $24 \mathrm{~h}$ on-duty physician at each floor, and set emergency beeper at the bedside in each guest room so that the residents can get timely help and salvation of they suffer pain or other emergent events.

\section{Applicability of atmosphere}

While we carry out specific interface design, furniture design, layout design, and color design for the indoor space of welfare institutes, in order to create a comfortable and warm living environment, and enhance residents' psychological sense of belonging, we shall avoid stylized design, and consider differentiated and individual design to actively cater to their personality features and psychological demand.

For example, the old people are calm and steady and they pursue for quietness, thus it is suitable to select soft color, furniture of classical model in their guest room and main activity space, the furnishings shall be mainly Chinese painting and calligraphy, plants and pot culture, and the wallpaper with comfortable sense of touching shall be selected; the overall atmosphere shall be 
simple Chinese style (as shown in Figure 3 and 4). The children are active and rich in curiosity. In consideration of cultivating their healthy psychology, it is suitable to select bright and vivid color matching, and furniture of curve-type circular-bead modeling. The furnishings shall be mainly cartoon, plastic or fabric animal toys, and the overall atmosphere can be countryside style or cartoon style. Furthermore, we can attempt to design boy's room and girl's room with different style according to different gender so that the room can meet different psychological feature and help children's growth.

The care for vulnerable groups shall be made from many aspects. Except that the government expands fund investment and the society provides help, it is required to continuously improve the facility condition of social welfare institutes, research the personality and emotion of service object, meet their behavioral and psychological demand, and create out the living environment of welfare institute which makes the old people and children feel satisfied and is full of humanistic care. This is the thing that the designer can and shall do.

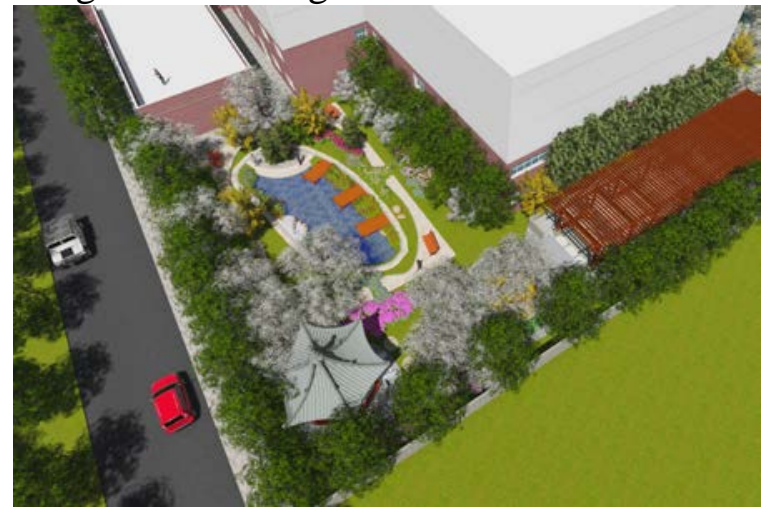

Figure 1

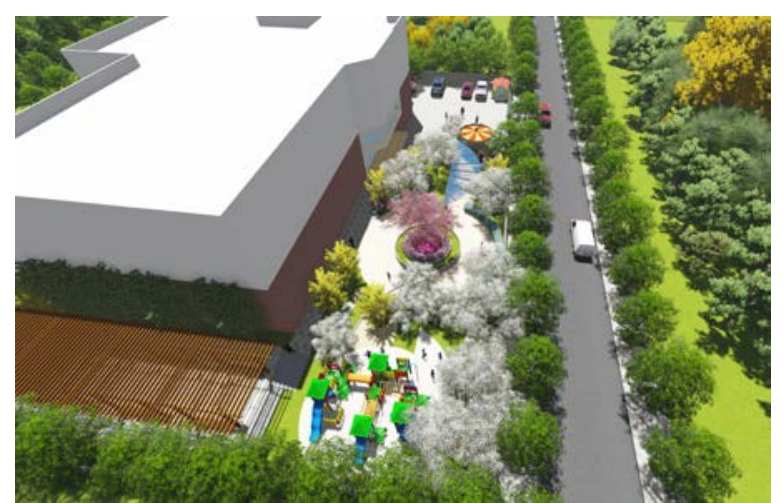

Figure 2

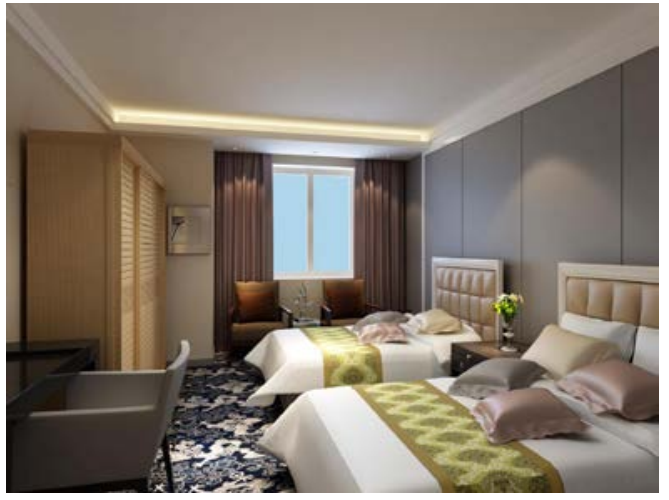

Figure 3

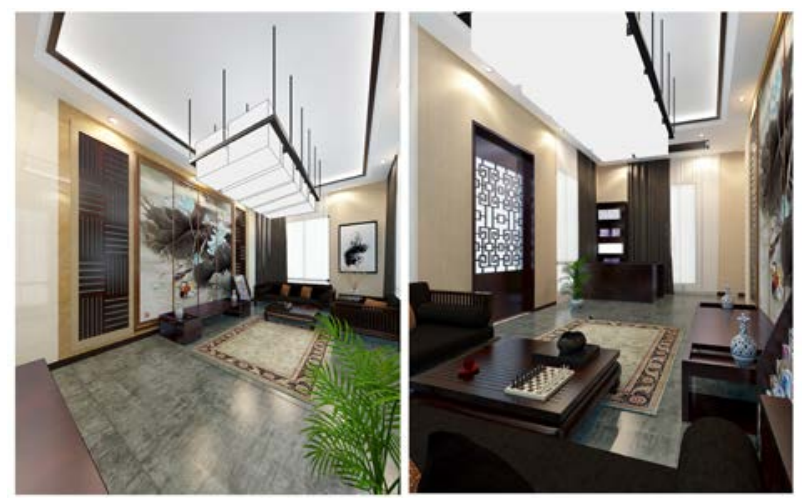

Figure 4

\section{References}

[1] Baidu Baike, http://baike.baidu.com., entry: aging of population 